\title{
In Retrospect: The earliest picture of evolution?
}

\section{Ideas about the mutability of species may have been part of Enlightenment imagery before Lamarck.}

De anima brutorum commentaria
(Commentary on the Soul of Animals)
by Francesco Maria Soldini
Gaetano Cambiagi: 1776

Illustrations can convey scientific ideas as effectively as the written word. It is widely accepted that there was no graphical representation of the evolution of species before 1800 , when the naturalist Jean-Baptiste Lamarck added the axis of time to his classification tree diagrams. However, I have found illustrations in a little-known book written by the Carmelite monk Francesco Maria Soldini that predate Lamarck's imagery. Plates in the book, published in Florence in 1776, clearly depict life emerging from the sea onto land.

Written in Latin, De anima brutorum commentaria is one of many books printed in the sixteenth and eighteenth centuries on the concept that animals have a soul. Soldini anchors his arguments to the writings of great philosophers from ancient times, such as Aristotle, and to scripture, especially the Book of Genesis. He was also influenced by contemporaries, notably Immanuel Kant, Gottfried Leibniz, Étienne Bonnot de Condillac and PierreLouis Moreau de Maupertuis. The book is a very rare volume and its scientific significance has escaped notice until now.

Soldini's book is embellished with eight stunning engravings by an unknown artist that depict natural scenes and animals, bound at the beginning of each chapter. The plates are printed in blue or red to contrast with the elegantly decorated initial letter of the text. But the iconographical content of the images is independent from the writing: many of the animal pictures are taken from the wood carvings of other treatises on zoology, such as those by the sixteenth-century naturalists Ulisse Aldrovandi and Conrad Gesner, which are not cited by Soldini. It is therefore likely that the plates were added separately to decorate the book, which was produced by Gaetano Cambiagi, typographer to the Grand Duke of Tuscany.

In two of the eight plates, the engraver portrays marine animals, mainly crustaceans, leaving the water and colonizing land. These images are reminiscent of the 'Neptunian' theory of Earth described by the French literary scholar and diplomat Benoît de Maillet (1656-1738). In his book Telliamed, which circulated for decades before being posthumously published in 1748, de Maillet explains how Earth was once entirely covered by water. He proposes that life began in the water in the form of minuscule seeds that joined together to create all aquatic forms, from which all terrestrial and winged creatures were then derived. In his opinion, all plants and ani-

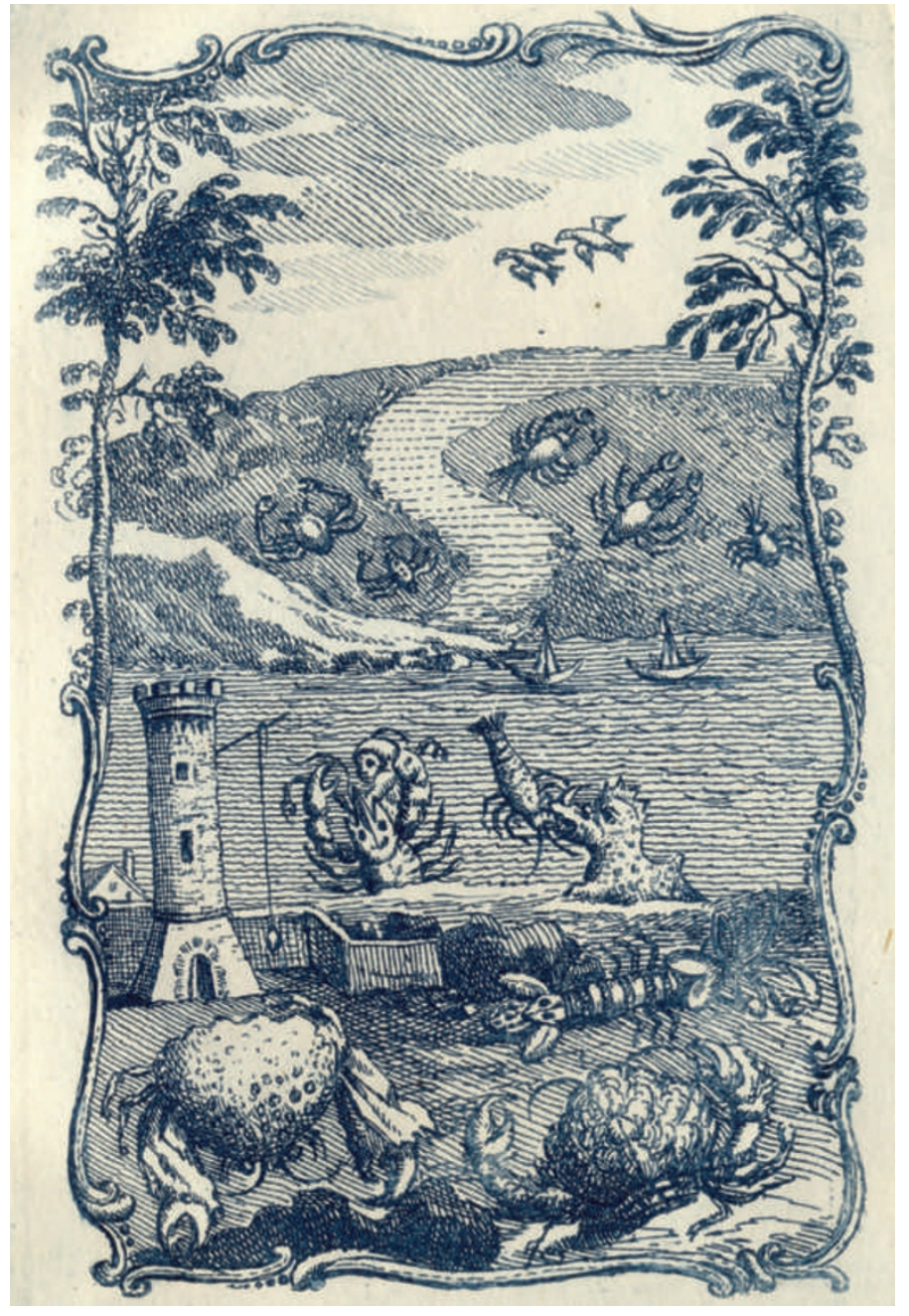

An engraving published in 1776, 83 years before On the Origin of Species. mals would have analogous examples among the aquatic specimens. The plates do indeed display marine animals that have parallels with species living on land, even in their names, such as the mantis shrimp and the fantastical marine rhinoceros. Yet Soldini makes no mention of either Telliamed or de Maillet in his otherwise highly referenced book.

A third plate represents images of fish taken from the iconography of the sixteenth century. They swim holding their heads above water with birds flying above. Such representations follow another de Maillet idea, that animals are derived from two basic types: the flying ones that live between the sea floor and the surface, which today is known as the pelagic zone, and the creatures that crawl on the sea floor, or benthic zone. Birds would have stemmed from the flying type, terrestrial animals from crawling forms.

The anonymous plates in De anima brutorum commentaria demonstrate the extent to which evolutionary ideas circulated during the Enlightenment, when drawing and carving were valuable means of transmitting progressive ideas to readers with minds open to novel concepts.

Fausto Barbagli is curator at the Natural History Museum of Florence University, Via Romana 17, I-50125 Florence, Italy.

e-mail: fausto.barbagli@unifi.it

See www.nature.com/darwin/index. html for more on Darwin.

Corrections
In the Book Review 'Amphibian
mystery misread' by Alan Pounds
and Karen Masters (Nature 462,
38-39; 2009) the sentence "Collins
and Crump's selection of published
work and quoted opinions
downplays such links" should
have read "Collins and Crump's
assessment of published work
and the opinions that they quote
downplay such links."
In Alison Abbott's Arts Review
'Florence's observatory restored'
(Nature 462, 40; 2009), "Pietro
Leopardo" should have read "Pietro
Leopoldo".

\section{Corrections}

In the Book Review 'Amphibian mystery misread' by Alan Pounds and Karen Masters (Nature 462, 38-39; 2009) the sentence "Collins and Crump's selection of published rk and quoted opinions and the opinions that they quot downplay such links." Leopoldo". 